\title{
A REVIEW OF APPLICATION OF SOME PRODUCT DEVELOPMENT TECHNOQUES APPLIED IN ENGINEERING INDUSTRY
}

\author{
A.R.Dandekar ${ }^{1}$, G.S.Joshi ${ }^{2}$, A.P.Shrotri ${ }^{3}$, S.B.Khandagale ${ }^{4}$ \\ ${ }^{1}$ M.E, Student, DKTE'S Textile and Engineering Institute, Ichalkaranjii, Maharashtra, India \\ ${ }^{2}$ Associate Professor \& P.G. Guide, DKTE'S Textile and Engineering Institute, Ichalkaranjii, Maharashtra, India \\ ${ }^{3}$ Associate Professor, PVPIT Budhgaon, Maharashtra, India \\ ${ }^{4}$ Assistant Professor, PVPIT, Budhgaon
}

\begin{abstract}
New product development is always challenging and creative task in today's era of globalization. Various internal and external factors are to be considered in the entire product development process. The concerned internal factors are skilled workforce with the organization, Budgetary provision for new product development, infrastructural and other resources available with organizations etc. While the external factors are requirement of the Customers, legal issues, Government policies, market segments and prevailing situations in the market. Considering the complexity in the product development process various new techniques of product development are being introduced by the industries, as well as proposed by researchers and academia. Lean product development, Quality Function Deployment, Six sigma is some of the techniques. In recent years there is a new technique being opted by the industry called as Advanced Product Quality Planning (APQP). This paper is an attempt to review the developments of $A P Q P$ and efforts being taken by the researchers in the development of $A P Q P$.
\end{abstract}

Keywords:-APQP, Six sigma, QFD, NPD techniques, APQP methodology, advantages of APQP $* * *$

\section{INTRODUCTION}

APQP or Advanced Product Quality Planning is the tool for new product development which is initiated and developed by the three Automotive giants, General Motors, Chrysler corporation and Ford during the 80's.Further they have formed the Automotive Industry Action Group(AIAG) for the research and development in the field of APQP. Initially the technique was used by the said Automotive giants and particularly in the field of Automotive industry. But after observing the advantages of APQP some other industrial sectors are also trying to implement it, After the introduction of the technique, various researchers are keenly interested in the study and analysis of APQP. Each researcher is dimensioning this methodology in own way. Owing to these different approaches all around the globe have added qualitative contribution in the entire development of APQP.

\section{EFFORTS BY VARIOUS RESEARCHERS}

1)Kapil Mittal et-al have studied about the implementation of APQP in small and medium size enterprises. This is a totally new approach; till then it was granted that APQP is the useful only for big giants and non-affordable and difficult to implement in small and medium enterprises. How ever they have not implemented it for the new product development. But it was concluded that the quality and performance of the existing product also can also be improved by implementation of APQP.A small component is selected for study, and the steps in APQP methodology are applied, such as Pareto analysis, FMEA and control plans .And finally it was concluded that APQP can also be implemented for existing product.
2) Yulia Surinova et-al have conducted the study regarding impact of globalization on the dynamic needs of customers. Due to the globalization customer is becoming very choosy and selective as well as particular about their demand. Hence the old approaches for new product development have certain limitations to satisfy the customers. By studying the automotive sector in Slovakia, she concluded that $\mathrm{APQP}$ is now the essential tool in the era of the globalization to satisfy the customer. It is now unavoidable for the industries to implement the techniques like APQP. For enhancing the product quality it is always necessary to implement this unique technique across the world.

3) Yulia Surinova has also studied the Global Product Development process. The GPD was developed from APQP. By studying an example from a Automotive giant, she has concluded that it not only helps to improve the quality but also useful from the point of the view of economy.

4) M. Bobrek et-al have discussed the implementation of $\mathrm{APQP}$ is one of the tool that can be used for standardization of management system design procedure. And it always helps to increase the efficiency of quality management system.

5)A.P.Shrotri et.al. have done research about PPAP. Production Part Approval Procedure or PPAP is one of the important process during the effective implementation of APQP .It is concerned with the documentation required which covers nearly all the important aspects of design, process, manufacturing, and quality control. According to him PPAP is an important part of product development process that allows the customer to evaluate his supplier without any fear of favor. 
6)A.P.Shrotri et.al. have further explained about the documentation of PPAP in detail where each and every document required to complete the procedure of PPAP is explained. According to which PPAP is the methodology that can reduce the shortcomings in processes accountable $f$ or rejection of material. It is better for both the suppliers as well as the customers to conduct the exercise of PPAP.

7) Thomas A. Carbone has emphasizes on an important point, that APQP is a philosophy which should be implemented by the all the constituents of the organization. Instead of detecting the problems in during the manufacturing, and the spending the time and money for rework, the problems can be avoided in the

second stage of APQP i.e. product planning.

8)Mark Lind has strictly said ,APQP is not only the process which is handled for quality control only, but it is the process or methodology which is applicable for new product development. It is not only the generation of documents. But it is an effort taken to deliver a quality product to the customer.

9)Junichi Tomita has studied about various new product development technologies and suggested that the Customer is now becoming an important factor in the entire process of new product development. Customer's demands are becoming special and sophisticated. Hence to satisfy the Customer, it become necessary for each and every organization to develop and implement the techniques of new product development like APQP, QFD (Quality Function deployment) \& Six sigma.

10)Milan Koval has studied about the agile product development. As per his conclusion the Customer in the future will be definitely well-informed about product quality and its function. Hence organizations have to change their policies and strategies. They have to invent, develop and implement various new product development techniques.

11)Miroslav Rusko has discussed about the implementation of Six sigma in the organization. He has discussed various advantages of the Six sigma process. As per the study done by him implementation of Six sigma helps the organization to reduce the wastage and to improve the performance of the organization.

12)M. Soković has also discussed about the implementation of Six sigma, but it is regarding the Automotive industry .The implementation of Six sigma helps the organization reduce the cost of quality. But it is very complex and tedious process to implement.

13)Eshan Jiaswal has studied about the Quality Function Deployment(QFD). The main advantage of QFD is that it reduces the development time and also encourages the teamwork within the organization. But there are certain limitations of QFD. It can not be applied in some sectors. Also some times while executing the QFD, it becomes difficult to transfer the Customer's needs in to the technical specifications.
14)A.P.Shrotri et.al. has discussed various approaches of new product development. Though Lean product development. Quality Function Deployment\& Six sigma are some of the effective methods for product development, they have their own limitations. However APQP is one of the methodologies, which avoids the limitations of the other relevant techniques and incorporates all the good features of them.

\section{CONCLUSION}

After studying the outcomes obtained by various researchers, it can be concluded that the customers, product quality and product cost and are the significant factors governing the new product development. To maintain the balance between these factors various new product development techniques like Lean product development, Six sigma, Quality Function Deployment are invented. The organizations are trying to implement these techniques as per their requirement, applicability and economical conditions. Advanced Product Quality Planning is one of the best techniques for new product development in now days. It incorporates all the advantages of Six sigma, QFD as-wellas Lean Product Development.

\section{PROPOSED WORK}

From the above discussions it seems that it has now become necessary to apply the APQP methodology for new product development for SMEs. The proposed research work aims at careful study and development of a new product using the methodology of APQP for a SME. The idea of proposed work has been discussed with Mr. S.S.Chitale (Technical Director) M/s Bhagyashree Accessories Pvt. Ltd. Pune INDIA $^{[15]}$ The company is an SME engaged in manufacturing of Automobile accessories. He has supported that the idea of new product development using APQP methodology will be beneficial for SMEs.

\section{ACKNOWLEDGEMENTS}

I would like to express my sincere thanks to Mr.S.S.Chitale(TechnicalDirectorBhagyashree Accessories Pvt. Ltd. Pune) for supporting the idea to implement APQP methodology for new product development in their industry. Also i would like to express my thanks to the employees of the said organization, especially Mr.M.B.Kulkrani \& Mr.Madhav Nikharage for providing me required assistance for the proposed work at BAPL. PUNE .INDIA.

\section{REFERENCES}

[1] Kapil Mittal, PrabhakarKaushik , Dinesh Khanduja ,'Evidence of APQP in Quality Improvement: An SME Case Study", International Journal of Management science, Volume 7, Issue 1, ISSN 1750-9653(England-UK), 2012, Pages 20-28.

[2]. Yulia SURINOVA, Iveta PAULOVA, "Globalization Effects On Specific Requirements In Automotive Production", Research Papers, Faculty of Materials Science And Technology In Trnava, Number 28,2010, Pages 101106. 
[3]. Yulia SURINOVA, "Ford system for cost reduction due to development time" http://www.mtf.stuba.sk/docs//internetovy_casopis/2009/1/s urinova.pdf

[4]. M. Bobrek, M.Sokovio, "Implementation of APQPConcepts In Design of QMS", International Scientific Conference On Achievements In Mechanical Engineering, Gliwice-Wisla,Poland, 16 th-18 th May 2005, Pages 35-38

[5]. Prof.A.P.Shrotri,Mr.A.R.Dandekar "PPAP an effective tool in vendor quality management", International Journal of Emerging Technology and Advanced Engineering,,Volume2-Issue4.April2012,Pg.369-372

[6]. Prof.A.P.Shrotri,A.R.DAndekar,S.B.Khandagale "Essential Requirements of PPAP" ,International Journal of Technological Exploration and Learning, Volume 3-number 3,June2014,Pg.502-505

[7]. Thomas Carbone, "Integrating Operations and Product Development Methodologies forImproved Product Success using Advanced Product Quality Planning", IEEE -ASMC April 2005Munich, Germany

[8]. Mark Lind ,Thomas Gill, "Secrets to Eliminating Disparate APQP Systems "a case study, AIAG,MayJune2005

[9]. Junichi Tomita, "Customer system orientation in the new product development process", World Conference on POM and ,Cancun, Mexico, April 30 - May 3, 2004

[10]. Milan Kováč, Lubica Kováčová et-al, “Techniques and tools for quality product design, http://katedry.fmmi.vsb.cz/639/qmag/mj106-en.pdf

[11]. .MiroslavRusko,RuženaKRÁLIKOVA, "Application of Six sigma method to EMS design", Research Papers Faculty of Materials Science and Technology Slovak University of Technology, 01/2011; 19(30):39-44. DOI: $10.2478 / \mathrm{v} 10186-010-0037-8$

[12]. M. Soković , D. Pavletić , E. Krulčić , "Six Sigma process improvements in automotive parts production",Journal of achievements in material and manufacturing

Volume19issue1,Novemeber2006,

Pg.96-102

[13]. Eshan S. Jaiswal, "A Case Study on Quality Function Deployment (QFD)", IOSR Journal of Mechanical and Civil Engineering, Volume 3, Issue 6 (Nov-Dec. 2012), Pg. 27-35, [14]. A.P.Shrotri, Prof.G.S.Joshi, Prof.S.A.Kore, A.R.Dandekar "A comparative study of APQP and contemporary product design and development stratigies", International Journal of Mechanical Engineering and Technology,Volume6-isssue 1,January2015,Pg.47-55

[15]. Product information of M/s Bhagyashree Accessories Pvt.Ltd PUNE INDIA athttp://www.bhagyashreeaccessories.com/centrifugal-oilcleaners-process--180536.html

\section{BIOGRAPHIES}

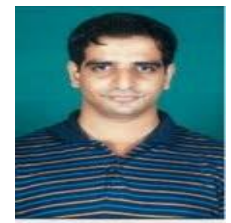

Mr. A. R. Dandekar, M.E. (Student) DKTE'S TEXTILE \& ENGINEERING INSTITUTE, Ichalkaranji, Maharashtra Course:-Product Design \& Development Email:-ashutoshdandekar@gmail.com

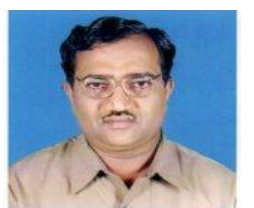

Since last eighteen years Prof. G.S.JOSHI is working as an Associate professor in DKTE ,Ichalkaranji (Dist.Kolhapur Maharashtra, INDIA). He has also professional experience of 6 Years in the Core industry. $\mathrm{He}$ is a graduate in Mechanical Engineering, and a post graduate in Mechanical Engineering with specialization in Power Engineering .He has published 8 papers in various international journals. Students have always obtained his helpful guidance for post graduation. Currently he is providing assistance for 8 Post Graduate students in their project work.

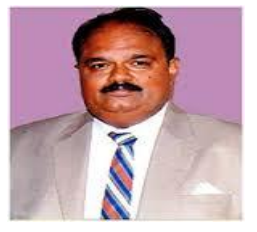

Prof. A.P.SHROTRI is working as an Associate professor in P.V.P.I.T.BUDHAON, Dist. Sangli, Maharashtra, INDIA since 1986 .He is a graduate in Mechanical Engineering, and a post graduate in mechanical Engineering, with specialization in Production Engineering. $\mathrm{He}$ has a remarkable teaching experience of 28 years . He has published thirteen papers at national level workshops and fourteen paper in international journals. He is the editorial board member of three international journals and worked on the board of reviewers of six international journals.

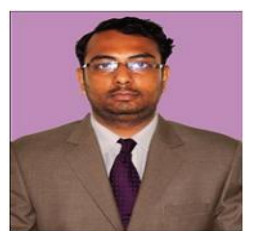

Mr.S.B.Khandagale, Assistant Professor in P.V.P.I.T.BUDHAON, Dist. Sangli, Maharashtra 